\title{
Carga de la prueba y El DEREChO A LA PRUEBA EN EL PROCESO DE RESTITUCIÓN DE TIERRAS"
}

\author{
Jorge Eliecer Cuesta Guerrero', Samir Hendrix Guerrero Pino II, \\ Marvin Cuesta Baldrich"II, Karen Alejandra Klinger Perea ${ }^{I V}$, \\ Jefferson Mena AnguloV, Yuranne Paola Valencia Lozano ${ }^{V I}$, \\ Lina Marcela Córdoba Córdoba ${ }^{V I I}$, Joel Antonio Moreno Luna ${ }^{\text {VIII, }}$ \\ Gustavo Murillo Cossio ${ }^{I X}$, Cristobalina Mena Moya ${ }^{X}$ \\ Tutores: Mario José Lozano Madrid y Héctor Manuel Hinestroza Álvarez
}

\section{RESUMEN}

La Constitución Política de Colombia en el artículo primero define el Estado como Social de Derecho, acto seguido garantiza la efectividad de los principios, derechos y deberes en ella consagrados, ello dentro de conceptos de justicia y equidad.

Fecha Recibido: abril 11 de 2014 • Fecha Aceptado: mayo 27 de 2014

* El escrito carga de la prueba y el derecho a la prueba en el proceso de restitución de tierras, es de autoría de los estudiantes arriba señalados utilizando diferentes medios de consulta claramente referenciados, respetando para todo los casos los derechos de autor que le asisten a los mismos. Igualmente, este artículo ha sido escrito estilo ponencia y posteriormente presentado en el trigésimo Cuarto Congreso de Derecho Procesal ante el Instituto Colombiano de Derecho Procesal (ICDP), ciudad Medellín (2013), bajo el título de la restitución de tierras como contribución a la reconciliación y la paz en Colombia.

I Estudiante de la Universidad Tecnológica del Chocó, Diego Luis Córdoba, Facultad Derecho, Séptimo (VII) Nivel. Miembro Activo del Consultorio Jurídico, Monitor de Curso Hermenéutica y Argumentación Jurídica, integrante del Semillero de Investigación de Derecho Procesal de la Universidad Tecnológica del Chocó, Diego Luis Córdoba.

II Estudiante de la Universidad Tecnológica del Chocó, Diego Luis Córdoba, Facultad Derecho, Decimo (X) Nivel. Miembro Activo del Consultorio Jurídico, Presidente del Semillero de Investigación de Derecho Procesal de la Universidad Tecnológica del Chocó, Diego Luis Córdoba. 
Con ocasión al conflicto armado interno, que por décadas ha padecido el Estado colombiano se origina el fenómeno del desplazamiento forzado, la flagrante vulneración del derecho internacional humanitario y de los derechos humanos; como consecuencia en 2011 surge la ley 1448, mecanismo de justicia transicional en pro de obtener la verdad, la justicia y la reparación integral, dentro del marco de protección especial de los derechos de las víctimas, para ello en el proceso de restitución de tierras es necesario la ponderación de principios probatorios como herramientas que orientan el desarrollo de dicho proceso, entre ellas la inversión de la carga de la prueba y la presunciones legales y derecho.

Palabras clave: Prueba, restitución, justicia transicional, víctima.

\section{Abstract}

The Constitution of Colombia in the article first defines the rule of law as Social thereupon guarantees the effectiveness of the principles, rights and duties enshrined therein, in keeping with principles of justice and equity.

III Estudiante de la Universidad Tecnológica del Chocó, Diego Luis Córdoba, Facultad Derecho, Séptimo (VII) Nivel. Integrante del Semillero de Investigación de Derecho Procesal de la Universidad Tecnológica del Chocó, Diego Luis Córdoba.

IV Estudiante de la Universidad Tecnológica del Chocó, Diego Luis Córdoba, Facultad Derecho, Decimo (X) Nivel. Integrante del Semillero de Investigación de Derecho Procesal de la Universidad Tecnológica del Chocó, Diego Luis Córdoba.

v Estudiante de la Universidad Tecnológica del Chocó, Diego Luis Córdoba, Facultad Derecho, Decimo (X) Nivel. Asistente Jurídico En la Oficina de Control Interno del Batallón de Combate Terrestre N. 94, Representante de Los Estudiantes Ante El Consejo de la Facultad de Derecho, integrante del Semillero de Investigación de Derecho Procesal de la Universidad Tecnológica del Chocó, Diego Luis Córdoba.

VI Estudiante de la Universidad Tecnológica del Chocó, Diego Luis Córdoba, Facultad Derecho, Decimo (X) Nivel. Integrante del Semillero de Investigación de Derecho Procesal de la Universidad Tecnológica del Chocó, Diego Luis Córdoba.

VII Estudiante de la Universidad Tecnológica del Chocó, Diego Luis Córdoba, Facultad Derecho, Séptimo (VII) Nivel. Integrante del Semillero de Investigación de Derecho Procesal de la Universidad Tecnológica del Chocó, Diego Luis Córdoba.

VIII Estudiante de la Universidad Tecnológica del Chocó, Diego Luis Córdoba, Facultad Derecho, Séptimo (VII) Nivel. Integrante del Semillero de Investigación de Derecho Procesal de la Universidad Tecnológica del Chocó, Diego Luis Córdoba.

Ix Estudiante de la Universidad Tecnológica del Chocó, Diego Luis Córdoba, Facultad Derecho, Séptimo (VII) Nivel. Integrante del Semillero de Investigación de Derecho Procesal de la Universidad Tecnológica del Chocó, Diego Luis Córdoba.

x Estudiante de la Universidad Tecnológica del Chocó, Diego Luis Córdoba, Facultad Derecho, Octavo (VIII) Nivel. Integrante del Semillero de Investigación de Derecho Procesal de la Universidad Tecnológica del Chocó, Diego Luis Córdoba. 
On the occasion of the internal armed conflict, which for decades has suffered the Colombian state originates the phenomenon of forced displacement and the flagrant violation of international humanitarian law and human rights, there is the 1448 law 2011, as transitional justice mechanism pro to obtain truth, justice and reparation, within the framework of special protection of the rights of victims, to do in the land restitution process is necessary weighting evidentiary principles as tools to guide the development of this process, including the reversal of the burden of proof and the legal presumptions and law.

Key words: Evidence, restitution, transitional justice, victim.

\section{INTRODUCCIÓN}

Estudiaremos el proceso de restitución de tierras en el marco del sistema de justicia transicional originado por las permanentes violaciones a los postulados del derecho internacional humanitario, en el Estado de Colombia, donde sus habitantes han padecido por décadas el conflicto armado interno ocasionando infortunadas consecuencias para sus asociados, como son las masacres, los homicidios selectivos y el fenómeno del desplazamiento forzado, estado de cosas, que ha conllevado al despojo y abandono de la propiedad, posesión y ocupación de predios, más que todo rurales, a lo largo y ancho del País, lo cual desdibuja la naturaleza esencial del Estado social de Derecho instituido en la Constitución Política de 1991.

Dentro de la estructura del sistema normativo el cual ha sido legislado para tiempos de paz, en armonía con la ley 1448 de 2011 y las normas internacionales que hacen parte del bloque de constitucionalidad, analizaremos sí la estrategia planteada para garantizar la verdad, justicia y reparación a las víctimas, contiene unas efectivas garantías procesales, como el derecho a la prueba y su inversión. Nos interesa con respecto a la ley de restitución, desentrañar el espíritu de sus principios, y la incidencia de ellos con los medios probatorios debidamente allegados al proceso para construir los presupuestos fácticos de las pretensiones y excepciones, criterios que deben tenerse en cuenta a la hora de valorar los elementos materiales de prueba en el proceso de restitución y generar de esta manera por una parte la eficacia probatoria, de otro lado la necesaria confianza legítima de los asociados, en los fallos de la nueva jurisdicción de tierras; teniendo como meta el esquivo ideal, de la pronta y cumplida justicia. Igualmente examinaremos las presunciones que blindan a las pretensiones de las víctimas en el proceso, y dentro de ese entendido los presupuestos para aligerar el derecho de prueba del actor, en la restitución a través de la valoración de la prueba sumaria, donde se traslada la carga de la prueba a su contraparte. Además las pruebas 
aportadas por la Unidad Administrativa Especial de Gestión de Restitución de Tierras Despojadas, cuando ésta represente a la víctima al ser fidedignas logran la convicción del operador jurídico en un grado de plena certeza.

Conforme a lo antes expuesto, en análisis de la Ley de Víctimas y de Restitución de Tierras, examinaremos las presunciones, de derecho y legales, la inversión de la carga de la prueba, el proceso de la restitución de tierras, en donde el operador jurídico tiene la facultad de suspender la etapa probatoria, es decir, los jueces están facultados para limitar la procedencia del decreto y práctica de pruebas en los procesos de restitución y de esta forma fallar anticipadamente.

\section{Planteamiento del problema}

Se justifica dentro del concepto de justicia transicional, el desequilibrio de la carga de la prueba a favor de la víctima en el marco del proceso de restitución de tierras el cual parte de una prueba sumaria como inicio y soporte de la pretensión, y en su desarrollo traslada las cargas probatorias al demandado aliviándose de esta forma al actor de un mayor compromiso probatorio que garantice el debido proceso y la igualdad de armas.

\section{Carga de la prueba y el derecho a la prueba en el PROCESO DE RESTITUCIÓN DE TIERRAS}

\subsection{Justicia transicional}

En un Estado que presenta situaciones de excesivas violaciones a los Derechos humanos por un prolongado conflicto armado interno y en el que el sistema normativo ordinario ha sido utilizado como instrumento para legitimar actos ilegales, tales como, despojos en apariencia de compraventas, posesiones y ocupaciones con aprovechamiento del abandono en razón del desplazamiento forzado, entre otros, que desbordan la estructura del sistema normativo vigente y legislado para tiempos de paz. De ahí que se haga necesario un nuevo sistema normativo, con características propias para enfrentar las consecuencias de dichas violaciones, conocer la verdad, administrar justicia, reparar el daño y tener la verosimilitud de construir un marco para la paz duradera.

Sistema normativo que se conoce como Justicia Transicional y que ha sido consagrado por la Corte Constitucional ${ }^{1}$ como un sistema o tipo de justicia de

REPÚBliCA DE COLOMBIA. CORTE CONSTITUCIONAL. Sala Plena. Sentencia C-052 del 08 de febrero de 2012. M.P. Nilson Pinilla Pinilla. Expediente D-8593. 
características particulares, que aspira a superar una situación de conflicto o postconflicto, se privilegia en el mayor nivel posible, los derechos a la verdad, la justicia y la reparación de las víctimas frente a un pasado de graves y sistemáticas violaciones de los derechos humanos. En el final propósito de encontrar lo que resulte conducente al logro y mantenimiento de la paz social. En este sentido la justicia transicional se ocupa de procesos mediante los cuales se realizan transformaciones radicales a una sociedad, que atraviesa por un conflicto o postconflicto, que plantean grandes dilemas originados en la compleja lucha por lograr un equilibrio entre la paz y la justicia; por su parte la ley 1448 de 2011, la define como los diferentes procesos y mecanismos judiciales o extrajudiciales, asociados con los intentos de la sociedad por garantizar que los responsables de las violaciones contempladas en el artículo $3^{\circ}$ de dicha ley, rindan cuentas de sus actos; se satisfagan los derechos a la justicia, la verdad y la reparación integral a las víctimas; se lleven a cabo las reformas institucionales necesarias para la no repetición de los hechos y la desarticulación de las estructuras armadas ilegales, con el fin último de lograr la reconciliación nacional y la paz duradera y sostenible.

Para Bickford ${ }^{2}$ citado por Djusticia "el término Justicia Transicional se refiere a aquella disciplina o campo de actividades que pretende aportar soluciones y herramientas a las sociedades para enfrentar un legado de violaciones a los derechos humanos que tuvieron lugar en un momento determinado de la historia -puede ser reciente o más lejano- con los objetivos de alcanzar la reconciliación nacional, contribuir a consolidar la democracia, reparar a la víctimas e instaurar una convivencia pacífica, en aras de que no se repitan los mismos hechos".

No obstante, como novedad a tales definiciones encontramos que la implementación de tal sistema normativo especial, a nivel global, es aplicado en etapas post-conflicto, sin embargo, ello no significa que éste sistema judicial no se pueda aplicar en tiempos de conflicto, como lo es en nuestro caso.

La ley 1448 de 2011 define víctima como aquella persona que de manera directa o colateral hubiere sufrido un daño, como consecuencia de violaciones al derecho internacional humanitario y lesiones graves a los derechos humanos,

2 BICKFORD, Louis. "Transitional Justice”. En: The Encyclopedia of Genocide and Crimes against Humanity, MacMillan Reference, USA, 2004, pp. 1045 a 1047. Véase, así mismo LANDMAN, Todd y ROBINSON, Neil (Eds.). The SAGE Handbook of Comparative Politics. Sage Publications, Londres, 2009, PP. 498 y 499.

3 LÓPEZ DÍAZ, Claudia; GONZÁLEZ, Diego. ERRANDONEA Jorge. Colombia: un nuevo modelo de Justicia Transicional, Editores por ProFis - Djusticia, ALVI IMPRESORES LTDA, 2012. p. 13. 
ocurridas con posterioridad al $1^{\circ}$ de enero de 1985 en el marco del conflicto armado.

Uno de los puntos destacado en esta definición es el hecho de establecer tres (3) tipos de víctimas. Dependiendo esta clasificación, de la fecha en la cual ocurrieron los hechos generadores de las violaciones al derecho internacional humanitario, su distinción tanto en derechos, como en acciones es de la siguiente manera:

- Víctimas antes del 1 de enero de 1985 solo tendrán derecho a la verdad, medidas de reparación simbólica y a las garantías de no repetición.

- Víctimas antes del 1 de enero de 1991 tendrán derechos a las prerrogativas otorgadas por la ley con excepción la restitución.

- Víctimas a partir del 1 de enero del 1991 tendrá derecho a las mismas prerrogativas y además de poder adelantar las acciones para la restitución con los mecanismos establecidos para estos efectos por la ley.

El elemento temporal incorporado en este concepto de víctimas ha generado cierta incertidumbre, puesto que en apariencia es devastador y atenta contra los derechos de las personas, que por las mismas condiciones establecidas en la ley, no reunieran los requisitos para ser víctimas. La Corte Constitucional se pronunció respecto de este asunto $^{4}$ y aclaro que los límites temporales no fueron establecidos de manera arbitraria, ni caprichosa, puesto que fueron fruto de un proceso de consulta y debate entre el Congreso, el Gobierno Nacional, diversos sectores políticos y la sociedad civil. Por lo tanto se debe respetar el margen de configuración legislativa.

\subsection{Proceso de restitución de tierras}

El Procedimiento de Restitución de Tierras establecido en la ley 1448 de 2011, inicia con el "Registro de tierras despojadas y abandonadas forzosamente" como instrumento para la restitución de tierras a que se refiere esta ley y el "Registro Único de Víctimas”. En el Registro de Tierras Despojadas y Abandonadas Forzosamente se inscribirán también las personas que fueron despojadas de sus tierras u obligadas a abandonarlas y su relación jurídica con estas, es necesario determinar con precisión los predios objeto de despojo, en forma preferente mediante geo-referenciación, así como el período durante el cual se ejerció influencia armada en relación con el predio. El registro se implementará en forma gradual y progresiva, de conformidad con el reglamento, para lo que se

4 RepúbliCA DE COlOMBia. CORTE CONSTItUCiONAL. Sala Plena. Sentencia C-250 del 28 de marzo de 2012. M.P. Humberto Antonio Sierra Porto. D-8590. 
tendrá en cuenta la situación de seguridad, la densidad histórica del despojo y la existencia de condiciones para el retorno. La conformación y administración del registro estará a cargo de la Unidad Administrativa Especial de Gestión de Restitución de Tierras Despojadas que se crea por esta ley. La inscripción en el registro procederá de oficio, o por solicitud del interesado. En el registro se determinará el predio objeto del despojo o abandono forzado, la persona y el núcleo familiar del despojado o de quien abandonó el predio. Cuando resulten varios despojados de un mismo predio o múltiples abandonos, la Unidad los inscribirá individualmente en el registro. En este caso se tramitarán todas las solicitudes de restitución y compensación en el mismo proceso. ${ }^{5}$

Una vez recibida la solicitud de inscripción de un predio en el registro por la parte interesada, o iniciado el trámite de oficio, la Unidad Administrativa Especial de Gestión de Restitución de Tierras Despojadas, deberá comunicar de dicho trámite al propietario, poseedor u ocupante que se encuentre en el predio cuya restitución se pretende, a fin de que pueda ejercer el contradictorio y de esa forma aportar las pruebas documentales que acrediten la propiedad, posesión u ocupación de dicho predio, además de ello acreditar su buena fe, conforme a la ley. La Unidad tendrá un término de sesenta (60) días, contados a partir del momento en que acometa el estudio, para decidir sobre su inclusión en el Registro. El anterior término, podrá ser prorrogado hasta por treinta (30) días, cuando existan o sobrevengan circunstancias que lo justifiquen ${ }^{6}$.

\subsection{Principios de la ley 1448 de 2011}

El Doctor Manuel A. Borja Niño ${ }^{7}$, define los principios como orientaciones sistemáticas, valorativas generales, consagradas técnicamente por el orden jurídico y que en forma tácita o expresa reciben concreción o se conllevan y efectivizan en unas normas procesales, o se abstraen, en forma general o particular, de las regulaciones atinentes a pruebas.

Teniendo en cuenta que nuestro objeto de investigación es, la carga de la prueba y el derecho a la prueba, en el Derecho Procesal Colombiano, más específicamente, en el proceso de restitución de tierras en Colombia; aterri-

5 INSTITUTO COLOMBiANO DE DESARROLlO RURAL (INCODER). "Capsulas de tierras para la paz”, 2012. Bogotá D.C. Información suministrada por la subgerencia de tierras rurales.

6 REPÚBLICA DE COLOMBIA. CONGRESO DE LA REPÚBLICA. Ley 1448 del 10 de junio del 2011, art. $76^{\circ}$. Primera Edición, Imprenta Nacional de Colombia.

7 BORJA NIÑO, Manuel A. La prueba en el Derecho Colombiano. Tomo I. Generalidades, derecho probatorio y acción probatoria. 
zaremos en el estudio de los principios de la ley 1448 de 2011, dicha norma enuncia principios que rigen y orientan su aplicación, donde hay algunos de gran relevancia, constituyéndose estos en una base sólida: para la justificación de las acciones afirmativas del régimen diferencial aplicado a las víctimas, desde el punto de vista procesal.

La Corte Constitucional, se ha pronunciado en torno a la pertinencia de estos principios y ha expresado "El principio de enfoque diferencial se traduce en la adopción de una serie de medidas encaminadas a enfrentar la situación de vulnerabilidad acentuada de algunas víctimas en razón de su edad, género, orientación sexual y situación de discapacidad. La ley ofrece especiales garantías y medidas de protección, asistencia y reparación a los miembros de grupos expuestos a mayor riesgo de violaciones de sus derechos fundamentales: mujeres, jóvenes, niños y niñas, adultos mayores, personas en situación de discapacidad, líderes sociales, miembros de organizaciones sindicales, defensores de derechos humanos y víctimas de desplazamiento forzado, y de esta manera contribuye a la eliminación de los esquemas de discriminación y marginación que pudieron ser la causa de los hechos victimizantes"8. En la ley 1448 de 2011, se encuentran enmarcados los principios desde el artículo $4^{\circ}$ hasta el $34^{\circ}$ algunos con mayor y otros con menor incidencia en el tema procesal, así podemos mencionar el de dignidad, como fundamento valorativo que soporta algunos de los fines de la ley y es base ideológica para la consecución de los mismos. Fines que deben ser atendidos no solo por dentro del contexto de la ley, sino también al interior de nuestro ordenamiento constitucional. Lo anterior encuentra respaldo, en nuestra carta magna tanto en su preámbulo, como en sus artículos 1, 2, 5, 12, 13, asumimos que hacerlo de manera distinta seria someter a las víctimas a rememorar los flagelos que han tenido que sufrir de una manera inclemente en el conflicto armado interno.

Es importante destacar los artículos 23, 24, 25 entre otros de la mencionada ley, ya que además de ser fines de la justicia transicional, la ley los consagra como principios de la misma, el derecho a la verdad, la justicia y la reparación integral, y así quedan de manera clara la necesidad de hacer valer los derechos de las víctimas, agregándole componentes importantes a estos mismos. En el caso del derecho a la verdad, establece que será imprescriptible e inalienable, que corresponde a la Fiscalía y a los organismos de policía judicial garantizar el derecho a la búsqueda de la víctimas, como presupuesto para la verdad, hasta tanto no sean halladas bien sea vivas o muertas.

8 REPÚBliCA DE COLOMBIA. CORTE CONSTITUCIONAL. Sala Plena. Sentencia C-253A del 29 de marzo de 2012. M.P. Gabriel Eduardo Mendoza Martelo. Expedientes D-8643 y D-8668. 
En el punto de reparación integral, se hace mención a las formas de reparación y de nuevo confirma que estas se realizaran de forma diferenciada, dependiendo de las condiciones temporales que caractericen a las víctimas "La reparación comprende las medidas de restitución, indemnización, rehabilitación, satisfacción y garantías de no repetición, en sus dimensiones individual, colectiva, material, moral y simbólica. Cada una de estas medidas será implementada a favor de la víctima en atención a la vulneración en sus derechos y las características del hecho victimizante" ${ }^{\prime \prime}$. Además hace aclaración de que por ninguna circunstancia, pueda confundirse las medidas de asistencia, con las de reparación y que por lo tanto, no podrá entenderse que las medidas de asistencia: serán descontadas de la indemnización administrativa o judicial a que tienen derecho las víctimas.

Del artículo 27 que hace mención a la aplicación normativa, podemos sacar varios apartes importantes como la prevalencia de lo establecido en los tratados internacionales ratificados por Colombia, sobre Derecho Internacional Humanitario y Derechos Humanos, que prohíban su limitación durante los estados de excepción, por formar parte del bloque de constitucionalidad. Que en los casos de reparación administrativa, consagra implícitos dos conceptos derivados del principio de favorabilidad, el de la norma más favorable y el de la interpretación más favorable, el intérprete de las normas consagradas en la ley se encuentra en el deber de escoger y aplicar la regulación o la interpretación que más favorezca a la dignidad, libertad de las víctimas, y derechos humanos de las víctimas.

El principio de la Buena Fe que inicialmente, se encuentra consagrado en el artículo 83 de la Constitución Política que a la letra reza: Las actuaciones de los particulares y de las autoridades públicas deberán ceñirse a los postulados de la buena fe, la cual se presumirá en todas las gestiones que aquellos adelanten ante éstas. Para algunos tratadistas como Valencia Zea, Buena Fe indica:

“(...) que cada cual debe celebrar sus negocios, cumplir sus obligaciones y en general, ejercer sus derechos, mediante el empleo de una conducta de fidelidad, o sea, por medio de la lealtad y sinceridad que imperan en una comunidad de hombres dotados de criterio honesto y razonable. La buena fe se desdobla en dos aspectos: primeramente cada persona debe usar para con aquel con quien establece una relación jurídica, una conducta sincera, vale decir, ajustada a las exigencias del decoro social; en segundo término, cada persona tiene derecho a esperar de la otra esa misma lealtad o fidelidad. En

9 REPÚBLICA DE COLOMBIA. CONGRESO DE LA REPÚBLICA. Ley 1448 del 10 de junio de 2011, art. 25 párrafo segundo. Primera Edición, Imprenta Nacional de Colombia. 
el primer caso se trata de una buena fe activa, y en el segundo, de una buena fe pasiva (confianza) (... $)^{10 ”}$.

El mencionado principio de la buena fe, es uno de los más relevantes, dentro del proceso de restitución de tierras. Dicho principio muta, y se presenta de manera diferente como podemos encontrarlo en la cotidianidad, se muestra desde aristas opuestas. En el primero de los casos se ve como es aplicado en forma regular al resumir la buena fe de las víctimas que hacen parte del registro único de víctimas. Situación que les otorga ciertos beneficios en la etapa probatoria como son, presunciones legales y de derecho en favor de ellas, en el lado opuesto del plano encontramos a los opositores de las pretensiones de las víctimas, a quienes se les presume la mala fe, la cual debe ser desvirtuada por estos durante el trámite procesal del juicio de restitución de tierras. Cabe anotar que estas presunciones no operan de manera generalizada ya que se deben llenar ciertos requisitos para que puedan configurarse; tema acerca del cual la Corte Constitucional expreso "el principio de buena fe está encaminado a liberar a las víctimas de la carga de probar su condición. En la medida en que se dará especial peso a la declaración de la víctima, y se presumirá que lo que ésta aduce es verdad, de forma que en caso de duda será el Estado quien tendrá la obligación de demostrar lo contrario. En consecuencia, bastará a la víctima probar de manera sumaria el daño sufrido ante la autoridad administrativa, para que esta proceda a relevarla de la carga de la prueba"11.

En el caso de los opositores, hablamos de una buena fe cualificada o exenta de culpa, que debe ser demostrada por parte del antagonista judicial del reclamante, para poder enfrentarse y desvirtuar las acusaciones de la víctima o por lo menos poder conseguir una compensación por haber actuado con lealtad y seguridad de conciencia y si se cometió error alguno este debió ser insalvable en condiciones normales, como lo plantea la corte constitucional "el error debe ser común a una generalidad de personas, y que ese error no lo hubiera podido descubrir, ni si quiera una persona que hubiese usado todos los medios para saber si la procedencia del bien era o no licita"12.

10 VALENCIA ZEA, Arturo. Derecho Civil. Tomo I. Parte General y Personas. Novena Edición. 1981. Editorial Temis Bogotá. Pág.196.

11 REPÚBliCA DE COLOMBIA. CORTE CONSTITUCIONAL. Sala Plena. Sentencia C-253A del 29 de marzo de 2012. M.P. Gabriel Eduardo Mendoza Martelo. Expedientes D-8643 y D-8668.

12 REPÚBliCA DE COLOMBIA. CORTE CONSTITUCIONAL. Sala Plena. Sentencia. C-1007 del 18 de noviembre de 2002. M.P. Clara Inés Vargas Hernández. Expediente RE-121. 


\subsection{Partes procesales}

Dentro del marco del proceso de restitución de tierras (ley 1448 de 2011. "Ley de Víctimas y Restitución de Tierras"), ostentan dicha calidad aquellas personas (individual o colectivamente), despojadas o que abandonaron sus territorios por el conflicto armado interno y, aquellas personas que como supuestos propietarios, poseedores $\mathrm{u}$ ocupantes actualmente se encuentran en el predio objeto de litigio (registro). De lo anterior, colegimos, son partes procesales: (i) las víctimas individual o colectivas, que perdieron la propiedad, posesión u ocupación del bien inmueble o predio, a causa del conflicto armado interno (ii) los presuntos propietarios, poseedores $u$ ocupantes del predio o bien inmueble objeto de registro por la unidad administrativa especial de gestión de restitución de tierras despojadas. Los primeros, actúan como titulares de la acción: actor o demandante, los segundos, como integrantes de la relación jurídica procesal, actúan en la arista de demandado u opositor.

\subsection{Terceros intervienes}

Todo el que no ha llegado al proceso como parte, en sentido formal, es tercero, aun cuando tenga la calidad de parte en sentido sustancial ${ }^{13}$. Al respecto, la ley 1448 de 2011 enlista los siguientes: "(i) las personas que tengan derechos legítimos relacionados con el predio (ii) los acreedores con garantía real y otros acreedores de obligaciones relacionadas con el predio (iii) así como las personas que se consideren afectadas por la suspensión de procesos y procedimientos administrativos que comparezcan al proceso y hagan valer sus derechos ${ }^{14}$.

\subsection{Legitimación en la causa}

Conforme con al artículo $81^{\circ}$, de la ley 1448 de 2011, observamos la institución procesal de la legitimación en la causa, la cual nos contrae a la capacidad para ser parte dentro de un proceso, es decir para poder comparecer en juicio.

\subsection{Legitimación por activa}

El Artículo 81 de ley 1448 de 2011, Legitima Por Activa, a: "Las personas que fueran propietarias o poseedoras de predios, o explotadoras de baldios cuya propiedad se pretenda adquirir por adjudicación, que hayan sido despojadas

13 QUINTERO, Beatriz; PRIETO Eugenio. Teoría General del Derecho Procesal. Cuarta Edición. Bogotá. Temis. S.A. 2008, p. 495.

14 REPÚBLICA DE COLOMBIA. CONGRESO DE LA REPÚBLICA. Ley 1448 del 10 de junio de 2011, art. $86^{\circ}$ literal e). Primera Edición, Imprenta Nacional de Colombia. 
de estas o que se hayan visto obligadas a abandonarlas como consecuencia directa e indirecta de los hechos que configuren las violaciones de que trata el artículo $3^{\circ}$ de la presente Ley; entre el $1^{\circ}$ de enero de 1991 y el término de vigencia de la ley, pueden solicitar la restitución jurídica y material de las tierras despojadas o abandonadas forzadamente...". También, a: "Su cónyuge o compañero o compañera permanente con quien se conviva al momento en que ocurrieron los hechos o amenazas que llevaron al despojo o al abandono forzado...".

Opera la sucesión procesal en estos casos: "Cuando el despojado, o su cónyuge o compañero o compañera permanente hubieran fallecido, o estuvieren desaparecidos podrán iniciar la acción los llamados a sucederlos, de conformidad con el Código Civil, y en relación con el cónyuge o el compañero o compañera permanente se tendrá en cuenta la convivencia marital o de hecho al momento en que ocurrieron los hechos". En cuanto a la capacidad para ser parte, la ley 1564 de 2012 en su artículo $53^{\circ}$, determina la legitimidad procesal; así mismo el llamado Código General del Proceso, en su artículo $54^{\circ}$. Inciso $1^{\circ}$ Expresa: "Las personas que puedan disponer de sus derechos tienen capacidad para comparecer por sí mismas al proceso. Las demás deberán comparecer por intermedio de sus representantes o debidamente autorizadas por estos con sujeción a las normas sustanciales". La ley 1448 de 2011. Art. 81, inciso $4^{\circ}$, regula la materia y al respecto, señala: "Cuando los llamados a sucederlos sean menores de edad o personas incapaces, o estos vivieran con el despojado y dependieran económicamente de este, al momento de la victimización, la Unidad Administrativa Especial de Gestión de Restitución de Tierras Despojadas actuará en su nombre y a su favor".

Igualmente la Ley de Restitución de Tierras, permite a las víctimas con capacidad para comparecer actuar directamente en el proceso de restitución, representados por persona idónea, o, "solicitar a la Unidad Administrativa Especial de Gestión de Tierras Despojadas que ejerza la acción en su nombre y a su favor" ${ }^{\prime \prime}$.

\subsection{Legitimación por pasiva}

La ley 1448 de 2011 -artículo 87- Legitima Pasivamente, a: "Quienes figuren como titulares inscritos de derechos en el certificado de tradición y libertad de matrícula inmobiliaria donde esté comprendido el predio sobre el cual se solicite la restitución...".

$15 \quad$ Ibídem. Art. $85^{\circ}$ inciso final. 


\subsection{Acciones}

Estos sujetos legitimados activamente en la causa, dentro del marco del proceso de restitución de tierras tienen como acción la restitución, la cual, puede terminar en jurídica y material del inmueble despojado, y además en subsidio, procederá, en su orden, la restitución por equivalente o el reconocimiento de una compensación. En la restitución jurídica y material del inmueble despojado, podrá restablecerse la propiedad o la posesión del inmueble según las circunstancias del caso. En aquellos casos de existencia de posesión, figura propia de la legislación civil, dentro del proceso de restitución: podrá declararse la propiedad del predio, si la víctima al tiempo de los hechos, cumplió los requisitos para adquirir mediante este modo de adquirir el dominio. Las víctimas que venían ejerciendo explotación económica en bienes baldíos, se les adjudicará la propiedad: si al momento del despojo o abandono, cumplieron con las condiciones para la adjudicación. A manera de colofón, el artículo $82^{\circ}$ de la ley 1448 de 2011, permite a: "los titulares de la acción pueden tramitar en forma colectiva las solicitudes de restitución o formalización de Predios Registrados en la Unidad, en las cuales se de uniformidad con respecto a la vecindad de los bienes despojados o abandonados, el tiempo y la causa del desplazamiento".

Derecho a la prueba

El artículo $29^{\circ}$ de la Constitución Política, contempla el ius fundamental del debido proceso, destacándose, entre otros principios, el de la contradicción. Premisa que rige la actividad probatoria, pues faculta a las partes para solicitar, presentar y controvertir pruebas; corresponde al juez, tras su práctica, la valoración de las mismas para formar su convencimiento. La Corte Constitucional ha dicho:

...La práctica de las pruebas, oportunamente solicitadas y decretadas dentro del debate probatorio, necesarias para ilustrar el criterio del fallador y su pleno conocimiento sobre el asunto objeto del litigio, así como las posibilidades de contradecirlas y complementarlas en el curso del trámite procesal, son elementos inherentes al derecho de defensa y constituyen garantía de la idoneidad del proceso para cumplir las finalidades que han sido señaladas en el estado social de derecho. ${ }^{16}$

16 REPÚbliCA DE COLOMBiA. CORTE CONSTITUCIONAL. Sala primera de revisión. Sentencia T-504 del 10 de septiembre de 1998. M.P. Alfredo Beltrán Sierra. Expediente $\mathrm{T}-176879$. 
En el nuevo procedimiento civil, el derecho a la prueba según el artículo $173^{17}$ opera dentro de la oportunidad probatoria, vale decir, en los términos establecidos por la norma, y por regla general halla génesis con la presentación y contestación de la demanda, donde las partes solicitan la práctica de las pruebas y el juez conforme a los requisitos de admisibilidad las decreta; incluso puede de oficio: ordenar la práctica de otras pruebas. Ahora bien, a la luz del canon constitucional y la reiterada y pacífica doctrina de nuestra insigne guardia constitucional, encontramos en el proceso de restitución de tierras ${ }^{18}$ una praxis del derecho a la prueba, a nuestro juicio, restringida y desequilibrada, hasta el punto de llegar a limitarlo muchas veces a extremos que probablemente generan conflicto de derechos e intereses; pero con justificaciones de que se trata de una relación procesal desnivelada por el conflicto armado interno de más de 50 años, la necesidad de la implementación del mecanismo de justicia transicional y matizado con los principios interpretativos "pro-víctima" y "pro-homine". Inclinándose el juez a una teoría que podríamos denominar "correcta interpretación" en la que como lo señala el jurista italiano Fiore y complementa la argentina Mónica Pinto "a causa de la necesaria imperfección de todas las cosas humanas, puede muy bien acontecer que resulte difícil adquirir idea exacta de la regla juris. (...). En semejante hipótesis, para bien aplicar la ley, corresponde al juez fijar y poner en evidencia el concepto preciso del legislador, adquiriendo idea clara, segura y completa de la disposición legislativa, mediante la interpretación misma" 19 "en virtud del cual se debe acudir a la norma más amplia, o a la interpretación más extensiva, cuando se trata de reconocer derechos protegidos e, inversamente, a la norma o a la interpretación más restringida, cuando se trata de establecer restricciones permanentes al ejercicio de los derechos o su suspensión extraordinaria. Este principio coincide con el rasgo fundamental del derecho de los derechos humanos, esto es, estar siempre a favor del hombre"20, y en el caso del juzgador de la restitución de tierras: del lado de las víctimas, tal como lo exteriorizó la Corte Constitucional al expresar que:

17 REPÚBLICA DE COLOMBIA. CONGRESO DE LA REPÚBLICA. Ley Ordinaria 1564 del 2012. Primera Edición, Imprenta Nacional de Colombia.

18 Ibídem.

19 FIORE, Páscuale. de la irretroactividad e interpretación de las leyes. $3^{\text {a }}$ Edición, Reus, traducción: AGUILERA DE PAZ, Enrique Madrid, 1927. p. 560.

20 PINTO, Mónica. "El principio pro homine. Criterios de hermenéutica y pautas para la regulación de los derechos humanos" [on line]. Archivo electrónico en la página del Programa de Naciones Unidas para el Desarrollo, Oficina en Venezuela. Disponible en la World Wide Web: http://www.pnud.org.ve/archivo/documentos/data/300/332j.htm. 
El derecho a la restitución implica, en términos generales, la obligación de ejecutar medidas para el restablecimiento de la situación anterior en la que se encontraba la víctima. En la citada ley se señala, adicionalmente, que una de las expresiones específicas del derecho a la restitución se manifiesta en el derecho a obtener la restitución de las tierras perdidas -reconocido en el artículo 72-, que comprende la obligación del Estado de adoptar las medidas que se requieran para la restitución jurídica y material de las tierras a los despojados y desplazados y, en caso de no resultar posible tal restitución, el derecho a obtener la compensación respectiva.

(...) vi)... (y) las autoridades judiciales deben garantizar la prevalencia de los derechos de las víctimas y, en especial, de aquellas particularmente vulnerables o que tengan un vínculo especial con la tierra ${ }^{21}$.

\subsection{Las presunciones de derecho}

La Ley de Víctimas y Restitución de Tierras -1448 de 2011- en el artículo 77, identifica las "presunciones de despojo en relación con los predios inscritos en el registro de tierras despojadas", estableciendo un catálogo de legales o juris tantum y de derecho o juris et de jure, es precisamente en las últimas que nos detendremos para analizarlas bajo el racero del derecho a la prueba.

Los numerales 1, 3, 4 y 5 del aparte normativo en cita, traen unas presunciones denominadas de derecho, la primera que al tenor literal reza:

2. Presunciones de derecho en relación con ciertos contratos. Para efectos probatorios dentro del proceso de restitución, se presume de derecho que existe ausencia de consentimiento, o causa ilícita, en los negocios y contratos de compraventa o cualquier otro mediante el cual se transfiera o se prometa transferir un derecho real, la posesión u ocupación sobre el inmueble objeto de restitución, celebrados durante el periodo previsto en el artículo 75, entre la víctima de este, su cónyuge, compañero o compañera permanente, los familiares o mayores de edad con quienes conviva, sus causahabientes con las personas que hayan sido condenadas por pertenencia, colaboración o financiación de grupos armados que actúan por fuera de la ley cualquiera que sea su denominación, o por narcotráfico o delitos conexos, bien sea que estos últimos hayan actuado por sí mismos en el negocio, o a través de terceros. La ausencia de consentimiento en los contratos y negocios mencionados en este numeral genera la inexistencia del acto o negocio de que se trate y la nulidad absoluta de todos los actos

21 RepúbliCA DE COLOMBia. CORTE CONSTITUCIONAL. Sentencia C-820 del 18 de octubre de 2012. M.P. Mauricio Morales Cuervos. Expediente D-9012. 
o negocios posteriores que se celebren sobre la totalidad o una parte del bien $^{22}$. En este evento por tratarse de una presunción de derecho tal como lo ha definido el último aparte del artículo 66 del Código Civil: "Si una cosa, según la expresión de la ley, se presume de derecho, se entiende que es inadmisible la prueba contraria, supuestos los antecedentes o circunstancias." Y tal como ya lo ha decantado la jurisprudencia nacional, no opera entonces el derecho a la prueba, la Corte Suprema de justicia en una añeja pero no por ello, desueta sentencia dijo: "Es claro que entre las anteriores categorías existe una variada gama de presunciones. Pero lo que las caracteriza y da fisonomía, es que la presunción juris et de jure, por fundarse en principios científicos incuestionables, no admite prueba en contrario; en tanto que entre las de naturaleza juris tantum o simplemente legales, hay unas que admiten toda clase de pruebas en contrario y otras que no admiten sino pruebas determinadas y especiales" (Corte Suprema de Justicia. Sentencia de junio 30 de 1939).

Igual pregón de imposibilidad probatoria se desprende del siguiente numeral del artículo 77 de la ley objeto de este trabajo:

Presunción de inexistencia de la posesión. Cuando se hubiera iniciado una posesión sobre el bien objeto de restitución, durante el periodo previsto en el artículo 75 y la sentencia que pone fin al proceso de qué trata la presente ley, se presumirá que dicha posesión nunca ocurrió”.

La anterior presunción aunque la ley que nos concita en esta ponencia, no la consagra expresamente como juris et de jure consideramos que lo es, ya que, el poseedor, no podrá demostrar nunca que su posesión fue de buena fe exenta de culpa, ni cualquier otra circunstancia, favorable a sus intereses, porque se presumirá que dicha posesión "nunca ocurrió", y puesta en el plano de la inexistencia el derecho de posesión que el tercero o el demandado pudiera manifestar que detentaba hasta la presentación de la demanda de restitución; se impide una controversia a la pretensión de restitución de la víctima, y se cierra el camino, conllevando entonces a una inexorable "tenencia de mala fe", por el aprovechamiento del conflicto armado. Impidiéndose incluso, el propio derecho de oposición, pues si es inexistente mi contrato de compraventa directo a la que manifiesta ser víctima, y también lo es mi derecho de posesión, no hay forma en que se pueda predicar una oposición dentro del proceso, ya que, en descenso de derechos respecto a la cosa, nos quedan el usufructo y la tenencia, los cuales de ningún modo impiden la restitución.

22 REPÚBLICA DE COLOMBIA. CONGRESO DE LA REPÚBLICA. Ley 1448 del 10 de junio de 2011, art. $77^{\circ}$. Primera Edición, Imprenta Nacional de Colombia. 
Cabría preguntarnos: ¿qué pasaría entonces en materia de las prestaciones mutuas que consagra el Código Civil? En concreto lo estipulado en los artículos 961 y 971, y en especial lo atinente a las expensas y mejoras, que hipotéticamente hubiera podido efectuar un poseedor de buena fe obligado a restituir a su legítimo dueño o poseedor. Debemos entonces mirar que se instituyen reglas legales cuyo propósito, es el de evitar el enriquecimiento sin causa del accionante o del mismo obligado a entregar el bien y en ese supuesto, apreciar la buena o mala fe de a efectos de definir el alcance de las prestaciones mutuas; criterios compensatorios que sin pruebas no serían dables.

En ese entendido, corresponde hacer un juicio de razonabilidad de dicha medida pero sobre la medida de que el derecho a la restitución, es un derecho fundamental ${ }^{23}$, el cual siendo parte de nuestro bloque de constitucionalidad, haya inicio en la legislación internacional y soporte interno en el texto de nuestra constitución, además de lo anterior se debe asumir la condición de vulnerabilidad y debilidad de la víctima frente al presunto despojador o desplazador, incluso juega para este test, la misma condición socio-económica de la víctima, que en normales condiciones, dentro de la realidad procesal se vería alejada y porque no privada del derecho a la prueba.

Además, la justificación de lo anterior en la acción de restitución, también se fundamenta en la circunstancia de aquellas personas que se han visto perturbadas, por acción del conflicto armado, directa o indirectamente en su propiedades o posesiones, bien sea por el despojo o por el abandono en contra de su voluntad de sus tierras; luego la acción de restitución es una herramienta judicial, que tiene como intención asegurar, que a través de un procedimiento judicial especial, sumario, eficaz y diferenciado, las autoridades establezcan si es viable o no: restituir un bien inmueble a una víctima o su núcleo familiar o herederos, y cuando haya lugar a la restitución: restableciendo en lo posible al desarraigado en las mismas condiciones previas al despojo; todo de ello dentro del cuadro de la justicia transicional.

\subsection{La víctima y la prueba en la ley víctimas}

El proceso de restitución inicia con una prueba sumaria aportada por la víctima, incluso el juez puede llegar al convencimiento con un simple indicio

23 REPÚbliCA DE COLOMBIA. CORTE CONSTITUCIONAL. Sala Octava de Revisión. Sentencias: T-821 del 5 de octubre de 2007. M.P. Catalina Botero Marino. Expediente T-1642563; T-159 del 10 de marzo del 2011. M.P. Humberto Antonio Sierra Porto. Expediente T-2858284; T-699A del 20 de septiembre de 2011. M.P. Humberto Antonio Sierra Porto. Expediente C-2710255; C-820 del 18 de octubre de 2012. M.P. Mauricio Morales Cuervo. Expediente D-9012. 
favorable al desarraigado, sin que dicho indicio, necesariamente haya pasado por el tamiz de la contradicción al interior del proceso judicial. La evidencia proveniente del despojado se encuentra revestida por una presunción de validez, correspondiéndole a quien se oponga a sus pretensiones, enervar probatoriamente dicha presunción, a efectos de poder alegar la falsedad de la prueba generadora de la acción.

Lo anterior debe analizarse desde la óptica del bloque de constitucionalidad y dentro del contenido de dicha teoría interpretativa se destaca uno de los instrumentos más relevantes para analizar, interpretar y precisar el alcance de los derechos que tienen las personas en situación de desplazamiento, y es la compilación de los Principios Rectores del Desplazamiento Forzado Interno, elaborada por el Representante Especial del Secretario General de las Naciones Unidas para el Desplazamiento Interno, Francis Deng ${ }^{24}$ como consecuencia de un estudio exhaustivo de las disposiciones jurídicas internacionales que amparan a este grupo poblacional, vulnerable, en especial conceden protección contra los desplazamientos arbitrarios, proporcionan acceso a la protección y asistencia durante los desplazamientos y garantías durante el regreso o el asentamiento y la reintegración sustitutivos ${ }^{25}$.

Lo explicado no quiere decir que las víctimas, a excepción de las tantas veces citada prueba sumaria, estén relevadas de probar. Así, la ley establece que la inversión de la carga de la prueba es un mecanismo que procede siempre y cuando la víctima pruebe sumariamente la propiedad, la posesión o la ocupación del predio y su situación de desplazamiento o de despojo. Además para que operen las presunciones de despojo se deben probar mínimamente los supuestos que las configuran. Sin embargo, el accionante en el evento de existir oposición, también podría presentar contrapruebas a las evidencias de dicho opositor, y en esto la víctima no está sola, ya que para ello el Estado, a través de la Unidad Administrativa Especial de Gestión de Tierras Despojadas, custodiará a la víctima en los juicios de restitución, p, además podrá designarle un abogado pudiendo además designarle un abogado que gratuitamente la asesore y la represente en el proceso.

24 ORGANIZACIÓN DE LAS NACIONES UNIDAS. Doc. E/CN.4/1998/53/Add.2, 11 de febrero de 1998. Informe del Representante Especial del Secretario General de Naciones Unidas para el tema de los Desplazamientos Internos de Personas, Francis Deng.

25 REPÚBliCA DE COLOMBIA. CORTE CONSTITUCIONAL. Sala tercera de revisión. Sentencia T-025 del 22 de enero de 2004. M.P. Manuel José Cepeda Espinosa. Expediente $\mathrm{T}-653010$. 


\subsection{A La prueba sumaria}

Conforme a lo antes expuesto, la Ley de Víctimas y de Restitución de Tierras, reconociendo, el entorno violento del despojo, la condición de vulnerabilidad y la dificultad para reunir y presentar pruebas, por parte de las personas que fueron despojadas de sus predios u obligadas a abandonarlos, adoptó el instituto procesal denominado "inversión de la carga de la prueba" ${ }^{26}$, desde el inicio del periplo de reclamo para la víctima y en acatamiento del principio de buena fe, se establece que el Estado debe presumir dicho presupuesto nomoárquico a favor de las víctimas y quiere significar que en el comienzo del proceso administrativo, ante la Unidad Administrativa Especial de Gestión de Tierras Despojadas, el solicitante puede acreditar el daño sufrido, por cualquier medio de prueba legalmente aceptado. En consecuencia, le basta al despojado probar de manera sumaria el daño sufrido ante la autoridad administrativa, para que al Estado proceda a relevarla de la carga de la prueba, debiendo asumir la mencionada Unidad el costo procesal de desvirtuar las aseveraciones fácticas del petente, lo anterior también se predica para un eventual opositor que irrumpa en el trámite administrativo.

En términos jurídicos la prueba sumaria es aquella que no ha sido sometida a contradicción, o confrontación y por ende no tuvo conocimiento de ella, la parte contra quien se quiere hacer valer, ya que no se ha debatido dentro de un proceso. Esto en términos más sencillos significa que es una prueba simple que acredita un hecho. Por ejemplo, para nuestro tema, sería una factura de pago de un servicio público o una copia de una escritura, o un contrato de compraventa, privado e informal, sería una prueba de la condición de poseedor de un predio o la constancia de desplazado también sería prueba de tal condición. Estas evidencias se llaman sumarias, porque no se han controvertido en ningún procedimiento, ellas de manera fácil y sencilla ayudan a acreditar un hecho, aunque sin demostrarlo de manera irrefutable ${ }^{27}$.

Esto implica que si aparece una persona que refute procesalmente al solicitante de la Restitución, es a éste opositor, a quien le corresponde aportar las pruebas que demuestren la falsedad de los argumentos de la víctima y fundamentar probatoriamente su oposición, acreditándose cómo adquirió el bien y que ésta adquisición la hizo actuando con buena fe exenta de culpa, es decir, sin

\footnotetext{
$26 \quad$ Ibídem, arts. 5 y 78.

27 Tomado de la cartilla La política integral de tierras: Restitución formalización y procesos agrarios en Colombia, 170 preguntas y respuestas presentada por el Ministerio de Agricultura y Desarrollo Rural, plenaria del Senado del 15 de mayo de 2012, p. 26, pregunta número 37.
} 
fraudes y sin aprovechamiento de la situación de violencia. El opositor podrá presentar sus argumentos y evidencias probatorias, ante el juez o magistrado de Restitución de Tierras y serán estas autoridades judiciales, las que al final del proceso decidan, conforme a al recaudo probatorio obrante: sí procede o no la Restitución y demás medidas complementarias.

\subsection{La inversión de la carga de la prueba}

Consagra la ley 1148 del 2011, en su artículo 77 una serie de presunciones, de derecho y legales, las cuales tienen por finalidad proteger los derechos de las víctimas, en específico el de la restitución de tierras, de la misma forma el artículo 78 de la ley arriba anunciada, de manera expresa consagra la inversión de la carga de la prueba, así mismo; este articulo determina que basta con la prueba sumaria de la víctima del despojo: para trasladar la carga de la prueba al demandado o a aquellos que se opongan a las pretensiones del titular de la acción de restitución. Significa lo anterior que se presenta una excepción al principio general del derecho de onus probando incumbit actori, según el cual al demandante le corresponde probar: los hechos en que funda su acción, empero en nuestro tema reiteramos, esa responsabilidad procesal, es del sujeto pasivo de la relación procesal.

\subsection{A Las presunciones del despojo}

El citado artículo 77 se ocupa de una serie de presunciones de despojo en relación con los predios. Así para su cabal entendimiento podemos agruparlas en dos tipos, unas que se fundamentan en situaciones subjetivas, pues tienen en cuenta al despojante y sus circunstancias personales, son las relacionadas con la presunción de derecho por existencia de condena penal, en contra de uno de los intervinientes en el negocio jurídico cuyo objeto era el bien pretendido en restitución; para que se configure la presunción aludida, la sanción penal debe ser por pertenencia, colaboración o financiación de grupos armados que actúan por fuera de la ley, cualquiera que sea su denominación, o por narcotráfico o delitos conexos, contenida esta presunción, en el numeral $1^{\circ}$ del artículo 77 de la ley víctimas, presunción de derecho, de la cual nos ocuparemos más adelante en el acápite correspondiente al derecho a la prueba.

Por su parte los numerales del segundo al quinto del artículo y la ley, ya previamente enunciados, establece una serie de presunciones legales en relación con ciertos contratos, actos, decisiones y situaciones, de la siguiente manera: 


\subsection{A.1 Presunciones legales en relación con ciertos contratos}

Salvo prueba en contrario, para efectos probatorios dentro del proceso de restitución, se presume que en los siguientes negocios jurídicos hay ausencia de consentimiento o de causa lícita, en los contratos de compraventa y demás actos jurídicos mediante los cuales se transfiera o se prometa transferir un derecho real, la posesión o la ocupación sobre inmuebles siempre y cuando no se encuentre que la situación está prevista en el numeral anterior, en los siguientes casos:

En cuya colindancia hayan ocurrido actos de violencia generalizados, fenómenos de desplazamiento forzado colectivo, o violaciones graves a los derechos humanos en la época en que ocurrieron las amenazas o los hechos de violencia que se alegan, causaron el despojo o abandono, o en aquellos inmuebles en donde se haya solicitado las medidas de protección individuales y colectivas relacionadas en la ley 387 de 1997, excepto en aquellos casos autorizados por la autoridad competente, o aquellos mediante el cual haya sido desplazado la víctima de despojo, su cónyuge, compañero o compañera permanente, los familiares o mayores de edad con quienes convivía o sus causahabientes.

Sobre inmuebles colindantes de aquellos en los que, con posterioridad o en forma concomitante a las amenazas, se cometieron los hechos de violencia o el despojo se hubiera producido un fenómeno de concentración de la propiedad de la tierra en una o más personas, directa o indirectamente; sobre inmuebles vecinos de aquellos donde se hubieran producido alteraciones significativas de los usos de la tierra como la sustitución de agricultura de consumo y sostenimiento por monocultivos, ganadería extensiva o minería industrial, con posterioridad a la época en que ocurrieron las amenazas, los hechos de violencia o el despojo.

Con personas que hayan sido extraditadas por narcotráfico o delitos conexos, bien sea que estos últimos hayan actuado por sí mismos en el negocio, o a través de terceros.

En los casos en los que el valor formalmente consagrado en el contrato, o el valor efectivamente pagado, sean inferiores al cincuenta por ciento del valor real de los derechos cuya titularidad se traslada en el momento de la transacción.

Cuando no se logre desvirtuar la ausencia de consentimiento en los contratos y negocios mencionados en alguno de los literales del presente artículo, el acto o negocio de que se trate será reputado inexistente y todos los actos o negocios posteriores que se celebren sobre la totalidad o parte del bien estarán viciados de nulidad absoluta.

Frente a propiedad adjudicada de conformidad con la ley 135 de 1961 y el Decreto 561 de 1989, a empresas comunitarias, asociaciones o cooperativas 
campesinas, cuando con posterioridad al desplazamiento forzado se haya dado una transformación en los socios integrantes de la empresa.

\subsection{A.2 Presunciones legales sobre ciertos actos administrativos}

Cuando la parte opositora hubiere probado la propiedad, posesión u ocupación, y el posterior despojo de un bien inmueble, no podrá negársele su restitución con fundamento en que un acto administrativo posterior legalizó una situación jurídica contraria a los derechos de la víctima. Para efectos probatorios dentro del proceso de restitución, se presume legalmente que tales actos son nulos. Por lo tanto, el juez o Magistrado podrá decretar la nulidad de tales actos. La nulidad de dichos actos produce el decaimiento de todos los actos administrativos posteriores y la nulidad de todos los actos y negocios jurídicos privados que recaigan sobre la totalidad del bien o sobre parte del mismo.

Presunción del debido proceso en decisiones judiciales

Cuando el solicitante hubiere probado la propiedad, posesión u ocupación, y el posterior despojo de un bien inmueble, no podrá negársele su restitución con fundamento en que una sentencia que hizo tránsito a cosa juzgada otorgó, transfirió, expropió, extinguió o declaró la propiedad a favor de un tercero, o que dicho bien fue objeto de diligencia de remate, si el respectivo proceso judicial fue iniciado entre la época de las amenazas o hechos de violencia que originaron el desplazamiento y la de la sentencia que da por terminado el proceso de qué trata esta ley. Para efectos probatorios dentro del proceso de restitución se presume que los hechos de violencia le impidieron al despojado ejercer su derecho fundamental de defensa dentro del proceso a través del cual se legalizó una situación contraria a su derecho. Como consecuencia de lo anterior, el juez o Magistrado, podrá revocar las decisiones judiciales a través de las cuales se vulneraron los derechos de la víctima y a ordenar los ajustes tendientes a implementar y hacer eficaz la decisión favorable a la víctima del despojo.

\subsubsection{Presunción de inexistencia de la posesión}

Cuando se hubiera iniciado una posesión sobre el bien objeto de restitución, durante el periodo previsto en el artículo 75 de la ley en cita, y la sentencia que pone fin al proceso de qué trata la presente ley, se presumirá que dicha posesión nunca ocurrión ${ }^{28}$.

$28 \quad$ Ibídem., art. 77 numeral $5^{\circ}$. 
Las anteriores presunciones hacen relación a circunstancias concretas con relación al bien que fue despojado, son ellas de naturaleza objetiva, así al presentarse prueba (sumaria de estos hechos), por ministerio de la ley, se presume por parte del funcionario judicial, la ilegalidad de los contratos, actos administrativos (adjudicaciones del INCORA, UNAT o INCODER) providencias judiciales y hechos, que produjeron solución de continuidad entre el nexo jurídico o material, existente entre el bien a restituir y el titular de dicha acción. Conviene apoyarnos en la distinción, hecha por el egregio filósofo del derecho Jeremías Bentham, entre hecho principal y hecho probatorio ${ }^{29}$, el primero indica el hecho que es objeto de investigación en un proceso donde las pesquisas van encaminadas a establecer si ocurrió o no tal hecho; por ende, ese hecho está en el pasado, y ya hoy, no existe tal cual como sucedió. El segundo tiene que ver con aquellos hechos del presente, a partir de los cuales se pretende dar vida o recrear la ocurrencia del hecho principal. En lo relacionado con la acción de restitución de tierras, tenemos que el primero sería el hecho del despojo o abandono forzado y el segundo la prueba sumaria de la que se vale el demandante, para acudir a la restitución de su inmueble.

De conformidad con lo anterior y por mandato de los artículos 5 y 78 de la ley de Víctimas y Restitución de Tierras, la carga de la prueba le corresponde al opositor -administrativo o judicial- de quien reclama la restitución del inmueble. De esta forma en los casos que el antagonista no logre desvirtuar la ausencia de consentimiento, en los contratos y eventos mencionados en alguno de los literales del artículo 77 de la ley, el acto o negocio de que se trate será reputado inexistente y todos los actos o negocios posteriores que se celebren sobre la totalidad o parte del bien, estarán viciados de nulidad absoluta ${ }^{30}$.

Pues bastará, con la prueba sumaria de la propiedad, posesión u ocupación y el reconocimiento como desplazado en el proceso judicial, o en su defecto, la prueba sumaria del despojo, para trasladar la carga de la prueba al demandado o a quienes se opongan a la pretensión de la víctima en el curso del proceso de restitución ${ }^{31}$.

\subsection{B El trato diferenciado en la carga de la prueba}

Es evidente la existencia de un desbalance probatorio, en la relación procesal de la acción de restitución, donde al accionante se le facilita probar, pues incluso

\footnotetext{
29 BENTHAM, Jeremías. Tratado de las pruebas judiciales. Paris T. 1. 1825, p. 16.

30 REPÚBLICA DE COLOMBIA. CONGRESO DE LA REPÚBLICA. Ley 1448 del 10 de junio de 2011, art. $77^{\circ}$ inciso e). Primera Edición, Imprenta Nacional de Colombia.

31 Ibídem., art. $78^{\circ}$.
} 
el Estado concurre a su favor en los ejercicios probatorios; y a contrario sensu, al opositor se le niega - presunciones de derecho- en unos casos el acceso al derecho de la prueba y en otros se le dificulta, pues se invierte la carga de la prueba (presunciones legales). Podría a prima facie, generarse cuestionamientos frente a la legitimidad del proceso y al indispensable acatamiento de las nociones constitucionales que gobiernan el principio del debido proceso y la igualdad. Pero este conflicto de derechos se empieza a zanjar, desde la misma ley 1448 del 2011, que en su principialistica dispone de la presunción de buena fe (artículo $5^{\circ}$ ) y el enfoque diferencial (artículo $13^{\circ}$ ), como categorías legitimantes de ese trato desigual, aunado a lo anterior, el concepto de justicia transicional (artículo $8^{\circ}$ ), de la misma manera la decantada jurisprudencia constitucional colombiana, sobre los derechos de las víctimas del conflicto, al igual que instrumentos internacionales, resaltándose dentro de ellos: la aprobación por la Sub-Comisión de Protección y Promoción de los Derechos Humanos de la ONU, en agosto del 2005, de los Principios del informe definitivo del Relator Especial, Paulo Sergio Pinheiro sobre Vivienda y Restitución de Bienes para los Refugiados y Desplazados, que fue un paso importante para ofrecer una orientación útil sobre los programas y mecanismos para la restitución a todo nivel de los bienes, para nuestro caso: los de las víctimas del conflicto.

Para abundar más, en cuanto a justificaciones de la inversión de la carga de la prueba a favor del sujeto vulnerable de la Litis, podemos citar mutatis mutandis la profusa jurisprudencia ${ }^{32}$ de la Corte Interamericana de Derechos Humanos, se resalta el efecto el siguiente aparte jurisprudencial:

La prueba indiciaria o presuntiva resulta de especial importancia cuando se trata de denuncias sobre la desaparición, ya que esta forma de represión se caracteriza por procurar la supresión de todo elemento que permita comprobar el secuestro, el paradero y la suerte de las víctimas.

(...)

A diferencia del Derecho penal interno, en los procesos sobre violaciones de derechos humanos, la defensa del Estado no puede descansar sobre la imposibilidad del demandante de allegar pruebas que, en muchos casos, no pueden obtenerse sin la cooperación del Estado.

(...)

La Comisión, sin perjuicio de haber utilizado otros elementos de prueba, aplicó, en el trámite ante ella, el artículo 42 de su Reglamento, que dice:

32 Ver fallos CORTE IDH: RADILLA PACHECO vs MÉXICO. Sentencia de 23 de noviembre del 2009; ALOEBOETOE y OTROS vs SURINAM. Sentencia de septiembre 10 de 1993. 
Se presumirán verdaderos los hechos relatados en la petición y cuyas partes pertinentes hayan sido transmitidas al Gobierno del Estado aludido si, en el plazo máximo fijado por la Comisión de conformidad con el artículo 34, párrafo 5, dicho Gobierno no suministrare la información correspondiente, siempre y cuando de otros elementos de convicción no resultare una conclusión diversa ${ }^{33 .}$

Por lo expresado no asoma duda, que invertir la carga de la prueba, a favor de las damnificados del conflicto interno nuestro, conlleva la realización de un verdadero ideal de justicia, así como a la finalidad de la reparación integral de la víctimas del enfrentamiento bélico interno y es un intento para equilibrar las cargas dentro de una confrontación procesal, entre un poderoso y un débil, al que el paso del tiempo y su misma vulnerabilidad socioeconómica lo alejan de la prueba, y el consecuente derecho al resarcimiento y la restitución.

\subsection{La sentencia anticipada en el proceso de restitución}

El artículo 89 de la ley 1448 del 2011, contempla que el Juez o Magistrado una vez llegue al convencimiento respecto de lo debatido, podrá abstenerse de decretar y practicar las pruebas solicitadas por las partes, profiriendo una especie de "sentencia anticipada", lo cual llegaría eventualmente, sino se maneja con la ponderación y razonabilidad debidos, a comportar una flagrante violación al derecho a la defensa y contradicción. Incluso podríamos pensar en una especie de pretermisión de la etapa probatoria.

Es conveniente acotar que la acción de restitución puede iniciar por la Unidad Administrativa Especial de Gestión de Restitución de Tierras Despojadas, donde por la misma naturaleza del proceso administrativo del Registro de tierras despojadas y abandonadas forzosamente -requisito de procedibilidad para la acción de restitución- se debe comunicar del inicio de dicho trámite al propietario, poseedor u ocupante que se encuentre en el predio objeto de registro, a fin de que pueda aportar las pruebas documentales que acrediten la propiedad, posesión u ocupación de dicho predio de buena fe, conforme a la ley. Lo anterior permite que de esta manera, se acopie un completo e integral paquete probatorio, con pruebas preconstituidas, obtenidas desde la actuación administrativa ante la mencionada Unidad; por lo tanto esto último nos permite hallar luces en las razones que motivaron al legislador, para otorgar dichos poderes discrecionales al Juzgador. Visión diferente nos generan aquellos sucesos, donde haya ausencia de oposición en el proceso de restitución, ya que

33 REPÚBLICA DE COSTA RICA. CORTE INTERAMERICANA DE DERECHOS HUMANOS. Caso VELÁSQUEZ RODRÍGUEZ vs HONDURAS. Sentencia de 29 de julio de 1988. 
al no haber debate probatorio, podría tener cabida el fenómeno que hemos denominado "sentencia anticipada" del proceso de restitución de tierras. Pero entrándose de circunstancias judiciales donde aparezca la lógica consecuencia de todo proceso contencioso, y aflore enfrentamiento a las pretensiones del actor, sería nugatorio del derecho a la prueba, que el juez, a mitad del debate probatorio, e incluso iniciando éste, prescinda de la actividad demostrativa procesal y acto seguido desate de fondo el litigio, sin practicar o peor aún, sin decretar las pruebas, tal actitud minaría eventualmente, la legitimidad del fallo y de la misma política pública de restitución, pudiera incluso caerse en el peor consejero de la autonomía funcional de los jueces y magistrados: el íntimo convencimiento.

\section{CONCLUSión}

Concluimos nuestro escrito observado que nuestro país, en el escenario mundial, se distancia del concepto clásico de justicia transicional, ya que ésta usualmente se ha planteado en escenarios post-conflicto, situación diferente a la aplicada en el Estado Colombiano, esto debido a las especiales condiciones del conflicto interno. De manera sui géneris en Colombia, se aplica durante el conflicto y además de forma novedosa se hacen extensiva esta noción de justicia, al campo civil, apartándose de la tendencia global, que orienta estos mecanismos a vías meramente administrativas y penales, en panoramas históricos posteriores al cese del conflicto. Queda claro la cimentación pro víctima, en que se funda la política estatal de restitución de tierras; orientación que se hace no solo justa, si no necesaria, por cuanto en la historia del flagelo de la violencia, sufrido en nuestro país, se desconocieron de manera sistemática los fines hacia los cuales el Estado debe propender en beneficio común, e incluso se utilizó el ordenamiento jurídico para cometer algunas violaciones a los derechos humanos, lo que trae como consecuencia actual, el posicionamiento jurídico del concepto de víctimas, dentro del contexto de la justicia transicional.

En el proceso de restitución de tierras encontramos varias particularidades procesales, que se separan de manera drástica del modo de operar tradicional de la justicia ordinaria, situación que haya razón por ser este proceso parte de un sistema de justicia transicional, tendiente a enmendar en cierta medida las graves transgresiones al derecho internacional humanitario, siendo esta la razón primordial para justificar eventos como la clara desigualdad de armas que pesa sobre los opositores o propietarios o poseedores del bien reclamado, ya que sobre ellos recae la carga de la prueba, puesto que deben desvirtuar las presunciones legales que operan en favor de las víctimas, en razón del régimen 
diferencial establecido por el legislador para el trámite judicial de la ley 1448 del 2011.

Aunque la palabra Geopatía, Derivada de los vocablos griegos "geo” (Tierra) y "pathos" (enfermedad, sufrimiento), no está registrada en el Diccionario de la Real Academia Española de la Lengua, ni ha sido clasificada como nombre de una enfermedad por la Asociación Colombiana De Psiquiatría, y su empleo se reduce más que todo a las practicas alternativas de la bioenergética, donde se emplea para denominar la afectación en la salud de la energía telúrica. Para el caso del conflicto colombiano cabría la oportunidad de acuñar este término, para unos compatriotas, en el último medio siglo, se han dedicado al desplazamiento y al despojo de tierras dentro del contexto social y político del conflicto armado colombiano; es este afán patológico por acumular tierras que ha sido un combustible incesante de la guerra civil. Y ahora con la creación de gavillas armadas anti-restitución, (herederas del fenómeno paramilitar) se oponen a sangre y fuego, al desarrollo judicial de la ley 1448 del 2011, al igual que a las reglas y principios del derecho internacional humanitario y demás instrumentos multilaterales del mundo civilizado, impidiendo un verdadero marco para la paz y la reconciliación.

La ley 1448 de 2011, desdibuja el principio de igualdad de armas, al cobijar con un blindaje especial a las pruebas de las víctimas en el proceso, blindaje que traslada a los opositores a un campo de imposibilidad probatoria, al determinar presunciones legales que en la práctica se tornan en presunciones de derecho, debido a la complejidad y a la particularidad en la obtención de los elementos probatorios que acrediten la buena fe exenta de culpa de la contraparte procesal del restituyente.

El artículo 89 de la ley 1448 de 2011, el cual otorga facultad a los operadores judiciales, de proferir fallo sin agotar el debate probatorio e incluso sin decretar pruebas, aquí el funcionario debe obrar con cuidado en estos aspectos, pues una actuación no ponderada y a la ligera, sobre todo en aquellos casos donde aparezca un contradictor judicial al reclamante, puede eventualmente conducir a una violación de manera flagrante al artículo 29 de la Constitución Política; al impedírsele, a la contraparte de la víctima, que pueda controvertir las pruebas allegadas en su contra, mediante un ejercicio dinámico y amplio de la actividad probatorio-procesal; en este supuesto se estaría transgrediendo el derecho de defensa que por vía jurisprudencial se ha determinado como un derecho intemporal, al cual no se le puede limitar su ejerció dentro de cualquier proceso. 


\section{REFERENCIAS}

\section{Doctrina}

CARNELUTTI, Francesco. Cómo se hace un proceso. Bogotá Ed. Temis S.A. 2007, pp. 55-56.

DEVIS ECHANDÍA, Hernando. Teoría General de la Prueba Judicial. Buenos Aires Ed. Fidenter. 1972, p. 186.

PARRA, QUIJANO, Jairo. Manual de derecho probatorio. Bogotá Colombia. Temis 3ed. 1992.

- Manual de Derecho Probatorio. Bogotá. Librería Ediciones del Profesional Ltda. Décima quinta edición, p. 142.

AZULA, CAMACHO, Jaime. Manual de Derecho Probatorio .Ed Temis. 1998, p. 24.

LÓPEZ DÍAZ Claudia, GONZÁLEZ Diego. ERRANDONEA Jorge. Colombia: un nuevo modelo de Justicia Transicional, Editores por ProFis - Djusticia, ALVI IMPRESORES LTDA, 2012, p. 13.

BORJA, NIÑO, Manuel A. La prueba en el Derecho Colombiano. Tomo I. Generalidades, derecho probatorio y acción probatoria.

VALENCIA, ZEA, Arturo. Derecho Civil. Tomo I. Parte General y Personas. Novena Edición. 1981. Editorial Temis Bogotá, p. 196.

QUINTERO, Beatriz, PRIETO, Eugenio. Teoría General Del Derecho Procesal. Cuarta Edición. Bogotá. Temis. S.A. 2008, p. 495.

BENTHAM, Jeremías (1825). Tratado de las Pruebas judiciales. Paris T. 1, p. 16.

FIORE, Páscuale. De la irretroactividad e interpretación de las leyes. $3^{\text {a }}$ Edición, Reus, traducción: AGUILERA DE PAZ, Enrique Madrid, 1927, p. 560.

\section{Artículos revistas}

BICKFORD, Louis. "Transitional Justice". En: The Encyclopedia of Genocide and Crimes against Humanity, MacMillan Reference, USA, 2004, pp. 1045 a 1047. Véase así mismo LANDMAN, Todd y ROBINSON, Neil (Eds.). The SAGE Handbook of Comparative Politics. Sage Publications, Londres, 2009, pp. 498 y 499.

INSTITUTO COLOMBIANO DE DESARROLLO RURAL (INCODER). "Capsulas de tierras para la paz". 2012. Bogotá D.C. Información suministrada por la subgerencia de tierras rurales. 
TOMADO DE LA CARTILLA. La política integral de tierras: Restitución formalización y procesos agrarios en Colombia, 170 preguntas y respuestas presentada por el Ministerio de agricultura y desarrollo rural en la plenaria del senado el 15 de mayo de 2012 P. 26, pregunta número 37.

ORGANIZACIÓN DE LAS NACIONES UNIDAS. Doc. E/CN.4/1998/53/ Add.2, 11 de febrero de 1998. Informe del Representante Especial del Secretario General de Naciones Unidas para el tema de los Desplazamientos Internos de Personas, FRANCIS DENG.

\section{Artículos red internet}

PINTO, Mónica. "El principio pro homine. Criterios de hermenéutica y pautas para la regulación de los derechos humanos" [on line]. Archivo electrónico en la página del Programa de Naciones Unidas para el Desarrollo, Oficina en Venezuela. Disponible en la World Wide Web: http://www.pnud.org.ve/ archivo/documentos/data/300/332j.htm.

\section{JURISPRUDENCIAS}

\section{Interna}

REPÚBliCA DE COLOMBiA. CORTE CONSTITUCIONAL. Sala Plena.

Sentencia C-052 del 08 de febrero de 2012. M.P. Nilson Pinilla Pinilla. Expediente D-8593.

RepúbliCA DE COlOMBiA. CORTE CONSTITUCiOnAl. Sala Plena. Sentencia C-250 del 28 de marzo de 2012. M.P. Humberto Antonio Sierra Porto. D-8590.

REPÚBliCA DE COLOMBiA. CORTE CONSTITUCiONAL. Sala Plena.

Sentencia C-253A del 29 de marzo de 2012. M.P. Gabriel Eduardo Mendoza Martelo. Expedientes D-8643 y D-8668.

REPÚBliCA DE COLOMBIA. CORTE CONSTITUCIONAL. Sala Plena. Sentencia. C-1007 del 18 de noviembre de 2002. M.P. Clara Inés Vargas Hernández. Expedientes RE-121.

REPÚBliCA DE COLOMBiA. CORTE CONSTITUCIONAL. Sala primera de revisión. Sentencia T-504 del 10 de septiembre de 1998. M.P. Alfredo Beltrán Sierra. Expediente T-176879.

REPÚBLICA DE COLOMBIA. CORTE CONSTITUCIONAL. Sentencia C-820 del 18 de Octubre de 2012. M.P. Mauricio Morales Cuervos. Expediente D-9012. 
REPÚBLICA DE COLOMBIA. CORTE CONSTITUCIONAL. Sala Octava de Revisión, Sentencias: T-821 del 5 de Octubre de 2007. M.P. Catalina Botero Marino. Expediente T-1642563; T-159 del 10 de marzo del 2011. M.P. Humberto Antonio Sierra Porto. Expediente T-2858284; T-699A del 20 de septiembre de 2011. M.P. Humberto Antonio Sierra Porto. Expediente C-2710255; C-820 del 18 de Octubre de 2012. M.P. Mauricio Morales Cuervo. Expediente D-9012.

REPÚBLICA DE COLOMBIA. CORTE CONSTITUCIONAL. Sala tercera de revisión. Sentencia T-025 del 22 de enero de 2004. M.P. Manuel José Cepeda Espinosa. Expediente T-653010.

\section{Externa}

Ver fallos CORTE IDH: RADILLA PACHECO vs MÉXICO. Sentencia de 23 de noviembre del 2009; ALOEBOETOE Y OTROS vs SURINAM. Sentencia de septiembre 10 de 1993.

REPÚBLICA DE COSTA RICA. CORTE INTERAMERICANA DE DERECHOS HUMANOS. Caso VELÁSQUEZ RODRÍGUEZ vs HONDURAS. Sentencia de 29 de julio de 1988.

\section{Disposiciones legales}

REPÚBLICA DE COLOMBIA. CONGRESO DE LA REPÚBLICA. Ley 1448 del 10 de junio de 2011. Primera Edición, Imprenta Nacional de Colombia.

REPÚBLICA DE COLOMBIA. CONGRESO DE LA REPÚBLICA. Ley ordinaria 1564 del 2012. Primera Edición, Imprenta Nacional de Colombia. 